\title{
CrimRxiv
}

\section{Are Campus Police "Real" Police? Students' Perceptions of Campus versus Municipal Police}

\author{
Andrea Allen 1
}

${ }^{1}$ Clayton State University

Published on: Jul 15, 2020

DOI: $10.21428 / \mathrm{cb} 6 a b 371 . b 9947246$

License: Creative Commons Attribution-NonCommercial-NoDerivatives 4.0 International License (CC-BY-NC-ND 4.0). 
Abstract: Campus police (CP) are an active force across U.S. universities. Yet, the public questions whether they are "real" police, as are municipal police (MP). Prior research finds students perceive CP and MP on different terms, and, generally, hold the former in lower regard. However, little is known about exactly how students view $\mathrm{CP}$ as different from and similar to MP. This paper addresses that gap by analyzing qualitative data gathered during interviews with 73 students attending a metropolitan Atlanta university. The analysis reveals participants perceive CP and MP as varying in training, powers, resources, sanction severity, and danger faced on the job. The paper concludes by discussing the broader implications, including how comparing CP to MP can improve research, theory, and policing.

\section{Introduction}

Campus policing dates to the 19th century and has greatly evolved since then (Bromley and Reaves, 1998; Fisher and Sloan, 2007; Gehrand, 2008; Peak et al., 2008; Sloan, 1992). Today, it is a major feature of the law enforcement apparatus in the United States. There are over 10,000 campus police (CP) serving at almost 4,000 universities making tens of thousands of arrests annually (Anderson, 2015; Reaves, 2008; USDOE, 2016).

Yet media headlines question whether CP are "real cops" like municipal police (MP). Examples include, "Are campus police officers 'real' police officers?" (Chronicle, 2015a), "What are campus police allowed to do?" (Chronicle, 2015b), "What is the real role of police on college campuses?" (Anderson, 2015), and "Campus police: real deal or rent-a-cops?" (Mayer, 2014). That such questions are even asked is important to the study of policing, given that theory and research suggest citizens' perceptions of officers' legitimacy affects their compliance with the law and how they interact with them (Tyler, 2006).

However, little research examines students' perceptions of CP in relation to MP. This paper addresses that lacuna by analyzing qualitative data obtained during interviews with 73 students attending a university in metropolitan Atlanta, Georgia, United States. In what follows, the next section describes the history of CP as well as how CP and MP vary concretely and in perception. After presenting the study's method and findings, the paper discusses their implications for future research and (campus) policing. 


\section{Campus Policing}

The history of CP dates back to the late $19^{\text {th }}$ century when Yale University hired two New Haven municipal policemen to patrol campus (Powell, 1994; Sloan, 1992). By the early $20^{\text {th }}$ century, campus policing had evolved into the night watchman style, with primary duties being facility maintenance and enforcing campus rules (Fisher and Sloan, 2007; Gehrand, 2008; Sloan, 1992). These CP, however, typically lacked law enforcement training, so local municipal police officers were called in when serious issues arose on campus (Gehrand, 2008).

That approach to campus security remained relatively unchanged until the 1960s. This new era arose from the first mass school shooting, namely that around the University of Texas Tower, and from widespread student protests against the Vietnam War and other social issues. In turn, university administrators selected experienced officers from municipal departments to develop, staff, and oversee campus enforcement operations (Fisher and Sloan, 2007). CP departments became more like MP departments in organizational and operational styles (Bromley and Reaves, 1998, 1999; Paoline and Sloan, 2003; Reaves and Goldberg, 1996). Additionally, state legislatures passed laws allowing universities to staff their own police departments with POST[1] certified sworn officers. This change meant CP now had the same police powers as MP, such as the ability to arrest suspects (Fisher and Sloan, 2007; Sloan, 1992).

During the late 1980s and early 1990s, campus policing transformed once again. This time, the spurring incident was the 1986 murder of Jeanne Ann Clery (Sloan and Fisher, 2011). She was raped, tortured, and strangled to death by a man, with whom she was not acquainted, who entered her dorm room in an attempt to burglarize it. According to reports, the perpetrator was able to enter Clery's room, because several of the building's doors had been propped open and left unlocked. A few years later, this incident resulted in the Clery Act, which requires universities to annually notify the public about incidents on campus and crimes known to CP. Clery's murder as well as media reports of lax campus security practices across the nation were catalysts in the legislation's adoption. Moreover, in response to negative publicity, CP departments began adopting community policing approaches to better prevent and respond to crime. In practice, this meant that CP became more proactive in their enforcement efforts, perhaps even more so than MP (Sloan and Lanier, 2007).

To gain a sense of where campus policing is today, consider the most recent findings from The Survey of Campus Law Enforcement Agencies (2011-12), which covers CP 
departments serving 4-year universities (Reaves, 2015a). About 68\% of officers are sworn. Entry-level, sworn CP completed an average of 1,027 training hours, compared to 1,370 such hours by MP (Reaves, 2010, 2015a). Jurisdictionally, 86\% of CP departments permit officers to make arrests on campus and adjacent property, and $35 \%$ permit CP to make arrests statewide. Seventy percent of CP departments have a mutual aid agreement or a memorandum of understanding with MP departments (Reaves, 2015a). Two-thirds of CP officers are armed and, thus, carry sidearms, batons, conducted energy devices (e.g., Taser), or chemical/pepper spray. Also, some $\mathrm{CP}$ departments authorize officers to use rifles, shotguns, bean bag rifles, rubber bullets, and flash/bang grenades. As in the past, primary functions of CP still include securing property and providing services to students like self-defense classes and escorting them around campus. However, CP have also become highly trained in their crime fighting ability. Between one-fifth and three-fifths of sworn CP are trained to perform special functions such as bomb/explosive disposal or detection; search and rescue; tactical operations (SWAT); task force participation; and underwater recovery. Training also prepares officers for large-scale incidents (e.g., terrorist attacks, natural disasters) on and around campus (Peak et al., 2008).

\section{Campus Policing versus Municipal Policing}

There are many similarities between CP and MP, but there are also distinctions. For one, CP must act in accordance with university administrators' expectations and preferences. To not deter enrollment at the university, administrators may ask or expect CP to keep the campus safe while, at the same time, avoiding aggressive tactics and severe sanctioning (Bordner and Petersen, 1983; Carr and Ward, 2006; Wolf et al., 2007). To accomplish these conceivably contradictory goals, CP are known to focus on policing persons unaffiliated with the university, or "outsiders" (Sloan and Fisher, 2011). This discriminatory system reflects the longstanding in loco parentis (act in place of the parents) doctrine of campus policing (Sloan, 1992; Sloan and Fisher, 2011), which contrasts with municipal departments' legalistic style of policing defined by a single standard of conduct punished in relatively uniform ways (Wilson, 1968).

Another difference between $\mathrm{CP}$ and MP is the latter tend to handle more serious crimes, especially compared to MP working in urban, socially disadvantaged areas (Miller and Pan, 1987). With that said, serious crimes do happen on campus, most of which are sexual and domestic assaults, followed by property offenses (Reaves, 2015a; Shorey et al., 2011; White House Task Force, 2014). Moreover, alcohol-involved crime is particularly widespread on and around campuses because, one, college students - 
including minors - drink frequently and in large quantities, and, two, alcohol intoxication increases the likelihood of being an offender or victim in alcohol-related crimes (Allen and Jacques, 2013; Dowdall, 2013).

Another unique facet of campus policing relates to university campuses being the place of several mass shootings. Though statistically rare, they capture the public imagination and cause widespread fear. Examples include the killings at Virginia Tech University, Northern Illinois University, Oikos University, and Santa Monica College. While both CP and MP face the threat of active shooters, it could be argued that this challenge is greater for CP because they operate with a lower officer-to-citizen ratio. The Survey of Campus Law Enforcement Agencies (2011-12) shows, for example, that there were an average of $1.4 \mathrm{CP}$ officers per 1,000 students at universities with 15,000 students or more, whereas there was an average of $2 \mathrm{MP}$ officers per 1,000 citizens in municipalities/townships with 10,000 to 24,999 residents (Reaves, 2010).

\section{Perceptions of Campus Police versus Municipal Police}

Potentially, students may think of CP and MP as one in the same, different in some ways but similar in others, or entirely distinct. To the author's knowledge, only two studies explicitly analyze this issue.[2] Wada and colleagues (2010) surveyed 593 undergraduate students at a large Pacific Northwestern university on their perceptions of CP and MP legitimacy. Results from a t-test showed that students attributed significantly less legitimacy to CP than to MP. And regression analyses indicated that students who are white and have higher levels of positive stereotyping were more likely to perceive both CP and MP as legitimate. Based on these results, the authors concluded that CP are marginalized compared to MP, or, in other words, "are not viewed as 'real' cops by the students they serve" (p. 127).

A drawback of Wada and colleagues' (2010) research is that they only asked students about their perceptions of CP or MP and then compared the mean scores. This is because one group of participants was administered a questionnaire solely about CP, whereas the other group was only asked about MP. Thus, one way to improve on their study is to ask each participant about CP and MP, as this may help researchers better understand how and why students view them as similar or different.

Uniquely, Jacobsen's (2015) study of “Mid-Atlantic U” qualitatively examined students' perceptions of CP legitimacy relative to MP. For this research, she conducted 8 indepth interviews and spoke with 4 focus groups of 4 participants each. Jacobsen found that students see CP as not performing “'real' police work” (p. 322). Some respondents 
also believed CP are less capable than MP; as one student expressed, "If you can't get a job at the state [police] department, you police at [Mid-Atlantic U]” (p. 322).

A potential critique of Jacobsen's study pertains to the sample size of 24 (8 interviewed and 16 in focus groups). However, this is less of a concern for her research because its goal was to shed qualitative light on an understudied topic, not to test a theory or produce results of a known statistical generalizability (see Jacques, 2014). Another limitation of her article is it lacks details on views of CP relative to MP. Presumably, this problem springs from the article's expansive coverage of multiple issues relating to CP, not only how they compare to MP. It follows, then, that a way to build on her work is by focusing entirely on perceptions of CP versus MP, as this should help elucidate a fuller range of views.

\section{The Current Study}

The above studies find that students perceive CP as different from MP or, more specifically, as not "real cops." Yet much is left to be known regarding the ways in which they see CP and MP similarly and differently. Thus, the present study addresses the following questions: In what ways do students view $\mathrm{CP}$ and MP as the same? In what ways different? And why? The answers are based on qualitative data obtained from a sample of 73 university students recruited via purposive and convenience sampling techniques. Among the participants, 85\% were black; 7\% non-white Hispanic; $4.2 \%$ white, $1.4 \%$ Asian/Indian, and $2.8 \%$ two or more races/ethnicities. Sixtytwo percent were female. Their ages ranged from 19 to 74 years, with an average of 30 years and median of 25 years. About a fifth are married and about a third have a child. In terms of college-specific characteristics, $4 \%$ were freshmen, $1 \%$ sophomores, $38 \%$ juniors, and the rest seniors; one-fifth lived on campus; and, only one participant was a member of a Greek organization.

Participants attended a 4-year, medium-sized public university in 2014. At the time of the study, enrollment was 7,261 students, 95\% of which were undergraduates and 44\% of which were enrolled part-time. The student body was $62 \%$ black, $23 \%$ white, and the remainder of another or unknown race/ethnicity. Sixty-eight percent were female. The average age was 28 years, and 34\% of enrolled students were "non-traditional," meaning at least 25 years old at the time of undergraduate matriculation. Sixty-four percent of the undergraduate students were awarded Pell Grants (USDOE, 2015), indicating a majority of them come from a disadvantaged background. The university is situated in a metropolitan county of Atlanta, Georgia, United States. In 2014, this county had a population of about 250,000 persons, of which $68 \%$ was black and $24 \%$ 
was white (USCB, 2015). The county's median household income was $\$ 40,606$, with about $24 \%$ of residents below the poverty level.

In 2014, the campus police department reported the following crime statistics: 3 sex offenses, 1 robbery, 4 cases of dating violence, 2 burglaries, 1 incident of stalking, and 2 motor vehicle thefts. There were no arrests for liquor law violations, yet there were 2 arrests for drug abuse violations and one arrest for illegal weapons possession. Additionally, there were, respectively, 22 and 26 judicial referrals made for liquor law and drug abuse violations, as well as 1 referral for illegal weapons possession. Though these numbers are low, it should be kept in mind that the actual number of campus crimes is likely far greater because many crimes go unreported or undetected. Regarding the county in which the university is located, in 2014 there were 590 violent offenses and 4,567 property offenses per 100,000 residents, compared to the nation's rates of 366 violent offenses and 2,596 property offenses per 100,000 persons (GBI, 2014; FBI, 2014).

As with CP at other universities, those working for the university under study are responsible for preventing, investigating, and sanctioning violations of the law and student code of conduct. At the time of data collection, the department employed 15 to 20 patrol officers from month to month.[]ㅡ These officers were divided into four teams, with each working twelve hour shifts. All officers were POST certified, carried firearms, and were "sworn-in" (i.e., had full arrest powers). Their jurisdiction included the university campus, which is about 200 acres in size, and up to 500 yards beyond the campus, all of which they patrolled by car and foot.

\section{Interviews and Analysis}

Data were collected from students during audio-recorded, semi-structured interviews. Typically, interviews lasted about 45 minutes and covered a range of topics revolving around participants' experiences with and perceptions of police, both campus and municipal. Pertaining to this paper, participants were asked a series of questions about their perceptions and understanding of CP versus MP.[4]] More specifically, participants were asked whether and how CP and MP vary, if at all, in (1) their capability to fight crime; (2) the extent to which they think they should possess the same powers, such as to arrest; (3) what powers they think they actually possess; and, (4) danger faced on the job. Collectively, these questions tap into police powers, capabilities, and performance, which are purported to influence officer legitimacy (see e.g., Sunshine and Tyler, 2003 and Tyler, 2002 for citizen perceptions of MP). Thus, by asking students those questions with respect to CP and MP, we should gain greater insight 
into how they compare in legitimacy. Of course, a different set of questions could lead to different results, so this should be considered when evaluating the study's findings.

Before the start of each interview, participants were made aware of their rights as a research subject, including that they would remain anonymous, could choose not to answer any question, and could terminate participation at any time. In addition to protecting participants and the study's ethical wellbeing, an added benefit of those safeguards is they may reduce the motive to lie or otherwise distort "the truth." Of course, distortion is a concern for any study based on self-report data. Thus, to further minimize that problem, participants were probed for details to help them recall events and illuminate unusual or seemingly baseless responses.

In preparation for analysis, each audio-recording was transcribed verbatim and then uploaded into NVivo 10. This qualitative software package allows for data to be coded with identification tags. Per inductive analysis techniques (e.g., Glaser and Strauss, 1967), the goal of analysis was to uncover what participants see as the major similarities and differences between CP and MP. During this initial round of coding, five themes became apparent: "Training"; "Resources"; "Powers"; "Sanctioning Severity"; and, "Danger." The next step in coding was to sift through those categories to determine how participants identified CP and MP as alike or different in each of those aspects. More about the coding process is described below because it ties in with the findings.

\section{Findings}

The second round of coding, described above, answered the question: In what ways do people view CP and MP as different? The answer to emerge is that participants cast CP as unlike MP in training, powers, resources, how severely they sanction, and danger faced on the job. At a basic level, these are the ways in which students view CP as less than "real cops." However, the third round of coding revealed that perceptions of CP versus MP are more nuanced than that. For one, this is because participants who perceived CP and MP as different in those ways held multiple views on how exactly so. For another, not all participants viewed CP and MP as distinct in the aforementioned ways. Instead, some individuals spoke to how CP are "real police," showing that not all students think of them otherwise. The paper now turns to a presentation of the qualitative data that produced and, thus, illustrate those findings. 


\section{Training}

MP and CP undergo training before becoming part of the rank and file, as well as over the course of their careers (Chappell et al., 2010). Though students were not directly asked about how CP and MP vary in training, this was a commonly discussed topic in interviews. For instance, some participants mentioned that CP and MP are trained differently. Participant 24 conjectured that "[CP] training might not be as extensive [as that of MP]." Though she spoke to the quantity of training, most participants who thought of CP and MP as different in this regard mentioned the type of training. Participant 43 summed up that idea when he said, "They are not trained for the same things." Such participants thought CP and MP are trained differently because of the type of "things" that happen on university grounds; to quote Participant 62, CP receive additional training "on how to deal with things that will typically happen on a college campus."

A common issue on campuses is drinking- and drug-related misbehavior, and, thus, Participant 43 thought "[CP are] trained to seek out things as far as like alcohol and stuff like that." Obviously, students are an indispensable feature of colleges, so while CP and MP "generally have the same training," said Participant 17, "I think campus police just have a little more student-based training." Participant 27 had the most expansive answer, as she referred to several of the potentially relevant factors that uniquely shape CP's training: "[CP are] trained to deal with the campus life, ... a certain age group, and certain stuff [that] might happen in such a closed area, ... [as] opposed to being on streets where other police [MP] are used to."

Yet not all students thought $\mathrm{CP}$ and MP receive different training. Rather, many participants figured they undergo the same training and obtain the same certifications. In the words of Participants 46 and 25, respectively, "They [CP] go through the same training and the same type of certification as a municipal police officer" and "[T]hey [CP] have the same sort of certifications and training as municipal police." Participant 25 noted, "[CP] have training for the situations that they may come in contact with just like municipal police." Participant 59 made a similar comment: "[T]hey [CP] are still mandated police officers so they still have the same type of training. I believe they still have to go to the police academy and everything like that." Similarly, Participant 6 said:

[T]o become a [campus] police officer I believe you have some of the same training that a regular city police officer would have. The training and the qualifications, the requirements to become a police officer, are pretty much the same. 
In discussing the similar training of $\mathrm{CP}$ and $\mathrm{MP}$, a couple participants specified that the only difference between these groups is their jurisdiction. Participant 21 commented, "[T]hey're the same, trained exactly the same. ... They're [CP] regular police that just happened to be assigned to the campus for however long." And Participant 9 echoed: "[T]hey [CP] go through the same training [as MP]. It's just where they're employed that's different. Campus police have to deal with just the campus and students, and municipal police kinda deal with what's going on out there."

\section{Resources}

As with training, all officers have resources they bring with them to the field. Yet, officers and departments differ in the quantity and types of resources to which they have access (Klinger, 1997; Reaves, 2015b). Though students were not asked about resources, this, too, frequently came up during interviews.

When resources were discussed, most students stated CP were lacking in this regard, compared to MP. Participant 55, for example, simply stated: “[T]hey [CP] don't have some of the resources that municipal police have to fight crime." Participant 27 also spoke in broad terms, though added that CP's lack of resources may make them dependent on MP in serious situations:

I think that campus police don't have as many resources as other [municipal] departments have. ... They might not be able to do certain stuff or perform certain actions. They might have to call for back up [from MP] for certain stuff, like say we have a bomb threat.

Related to that example is Participant 2's contention that "[CP] don't have the man power that the municipal does." Participant 26 mentioned that they not only lack "man power," but also detection dogs: "I don't believe that they [CP] have the resources to fight the kind of crime municipal police fight, such as [by having] more police officers and maybe a canine unit for drug-related cases." And Participant 41 went beyond hypotheticals when she drew on her knowledge of how CP resources affected their handling of an actual bomb threat on campus:

[There was a] bomb threat that got called in, in 2010. ... They just had the campus police walking around, basically like Barney Fife going around. They don't have the personnel, I believe, to handle something like that. I think they do need to hire more personnel to do that, or have a co-op between [with local police departments] or even the Sheriff's Department to shut down the campus and do a room by room search if it's needed. You could move freely around campus and I've 
never seen that in a facility that was supposed to be locked down after a bomb threat.

While most participants perceived CP to have fewer resources than MP, some students deemed them more or less equals here. Participants 28 and 53 said, respectively, "[C]ampus police are fully equipped as well as municipal police" and "[T]hey have the resources that most municipal police have." Though perhaps lacking in personnel, students commented that CP and MP are similar in that they both have weapons, bulletproof vests (Participant 10), and police cars (Participants 10 and 31). For example, Participant 47 noted, "They are definitely equipped with the same weapons." Participant 31 elaborated on that comparison: "I don't see that they're [CP] any less armed. ... I think they have handguns. I think they have batons. They may have pepper spray. They might have Tasers."

\section{Powers}

Policing powers amount to the legal right of officers to enforce the law, maintain control of the public, apprehend suspects, and use force if necessary (Bittner, 1990; Brown, 1981; Manning, 1977; Muir, 1977; Westley, 1970). As seen in the media headlines quoted at this paper's outset, questions about CP often pertain to their powers. Thus, it should come as no surprise that some participants thought CP have less power than MP. "I'm thinking," said Participant 48, "the municipal police might have a little bit more authority than the CP." And Participant 24 explained, "[W]hen you think about campus police, you think about security. You don't really think of anything like, this is a 'police.'”

Some students questioned or denied that CP can arrest suspects as can MP. For example, Participant 22 stated, “I think that campus police wouldn't have as much authority as municipal police, so I think that they wouldn't be able to do as much [sanctioning wise]." Participant 48 asserted, "I think the campus police are kind of limited to what they can arrest people for." And Participant 52 perceived CP to have limited powers, explaining: “I just think [they] have enough power ... to say 'Don't do this, don't do that', but not really to take someone to jail." Participant 28 made a similar comment, while adding that their investigative powers are limited, too:

I'm not totally sure what all campus police can do, but I don't know if he can just go out on the street and arresting people or clocking them for speeding or doing whatever a regular police officer can. He has some of the powers, not all. 
Among participants who spoke to CP and MP having different powers, another common- and, indeed, obvious - issue mentioned was their respective jurisdictions. Participant 37 alluded to this when remarking, "They are still police officers, [but] their jurisdiction is just the campus," and Participant 56 specified CP "have the same power" as MP except "just in the area where the campus is at." "CP act like cops ... [and] look like cops," observed Participant 32, "but, yet, they're only limited to this area, so I guess their job comes with limitations."

As alluded to by the above participant, the thinking of students was that MP can police on campus, but CP cannot police outside that territory. Participant 17 reflected, for example, "I think they [CP] have less power. ... I just feel like they don't have the full range, full scale of power. They can't go out in [the surrounding county] ... and make an arrest." Participant 23 went a step further by adding that if a very serious crime were to happen on campus then MP would take control of the case:

There's some crimes that the campus police would have to call a municipal police [to handle], I believe. I don't know how the system works, but if they had a murder on this campus, and I hope they never do, or any other campus, the municipal police would have to get involved, because it becomes not just a campus issue, but a county and state issue, ... so they would have to call in reinforcement, and they would have to call in people who would deal with the municipal [context], not just the campus. ... Again there are certain issues that occur on campus that would have to involve the municipal police. I'm not sure if they can take the same actions other than detaining someone, but as far as the paperwork, the reporting, I think that would be extended to the city and the county and probably the state. There are certain things that campus police would not be able to just keep on campus. Certain cases, I think, extends to the municipal police.

Several participants, however, believed CP and MP possess similar powers. Participants 61 and 52, respectively, commented that CP "have the ability to do everything a municipal police does" and "[CP] have the same powers and rights as municipal police." Tying back to the prior section on resources, a couple participants said that $\mathrm{CP}$ and MP are similar in powers in that each has, and can use, firearms. Both "carry guns and [can] shoot somebody," said Participant 29. And to Participant 50, CP and MP "have the same power to draw their weapons when they feel threatened."

Other participants referred to the power to arrest. Participant 18, for example, said “[CP are] just like municipal officers. They've been sworn in to do what they're 
supposed to do. ... [T] hey're police officers. They're not security guards." Participant 44 noted, "They [CP] have the same power to fight the crime as municipal police as far as arresting and ticketing, and that sort of thing." Participant 62 was less sure of how $\mathrm{CP}$ and MP compare in powers, but reasoned "[i]f they can arrest you, I think they [CP] have the same power." Participant 6 engaged in a similar form of reasoning, while also referring to $\mathrm{CP}^{\prime} \mathrm{s}$ investigatory powers:

I think that [they have similar powers] because they both have the right to handle situations where - if it gets out of hand - they can arrest or do whatever is necessary. They can come into your dorm room, your dwelling, your apartments if they feel that something is suspicious. They can ask [questions], they can stop you, they can check your car; they can do everything that the city police can.

\section{Sanctioning Severity}

When an officer finds evidence of lawbreaking, they have a few choices for how to handle the case. Depending on the situation (evidence, priorities, etc.), they may impose no sanction, give a verbal or written warning, document an individual's information, issue a trespass warning, write a ticket, or arrest the suspect (Author, XXXX). Moreover, often CP have the option to issue a student disciplinary action, which notifies the university's judicial board/committee of an offense that, in turn, they may sanction with community service, expulsion, or other punishments.

As reviewed above, participants recognized that $\mathrm{CP}$ and $\mathrm{MP}$ are alike in their power to sanction offenders. At the same time, however, students were unanimous in the perception that MP are far more prone to sanction offenders, especially in a severe manner. "I would say the campus police would be more lenient than [MP]," remarked Participant 13. And Participant 12 suggested, "[T]he on-campus police may have a little bit more leniency [than MP]."

Participants offered a few interrelated explanations of CP's and MP's differing sanctioning propensity. In effect, what students suggest is that the nature of being a CP officer shapes their sanctioning decisions. One aspect of the theory was that CP are more understanding of "college life" as a "party lifestyle" (see, e.g., Vander Ven, 2011; Weiss, 2013) and, therefore, more likely to leniently punish infractions of that ilk. Consider the following quotes:

Participant 57: I feel like some of the campus officers are more lenient than the officers out there [in the municipality]. The campus police understand more what 
goes on on-campus, like with drugs and alcohol. You might be able to get away with more with them.

Participant 5: I feel as though some crime, some things they [CP] let slide; ... they let students get away with [things] as opposed to [what] a municipal police [would do]. ... [S]ome crime campus police are more lenient [about]. ... I guess they understand the environment, and they understand that this is college, and there are parties, drugs, sex, all of that, where I feel like municipal police would be more harsh on those type of crimes, especially with, I think, things that should be misdemeanor crimes, like weed or marijuana. I feel like municipal police takes stuff like that more serious than campus police.

Another component of the theory is that CP are better acquainted, or at least on better terms, with the persons they police than MP are with the population they serve. Participant 45 spoke to this possibility: "They [CP] know the campus. And sometimes they may know the students. Knowing them [students] sometimes they can say, 'They're not a horrible person. They made a mistake.'” Likewise, Participant 61 conjectured that because CP know students, "they are able to deal with situations [without issuing severe sanctions] where a municipal officer would just come and lock somebody up."

The third aspect of students' theory of sanctioning by CP versus MP ties in with the first two aspects. CP, according to participants, are more willing to give offenders a "second chance" instead of issuing a severe sanction the first time around. CP may be likelier to give second chances due to understanding the nature of college life, being acquainted with students, or, more generally, seeing themselves as part of the university apparatus meant to help people advance from students to educated and employed members of the wider community. Participant 8 talked at length about these possible influences on CP compared to MP sanction severity:

I think campus police give more warnings than they do like arrests or anything. I think they try to give people, the students, opportunity. That's a good thing about campus police 'cause they just don't arrest. ... [Whereas] the municipal officer ... [might] just say, "We'll lock them [students] up, we'll give you this fine, we'll throw you in jail." Campus police ... try to work with students 'cause ... they're not trying to put the students under bad cause [hurt them]. They're actually trying to help 
students out: "We're gonna give you a warning," and they'll give mostly warnings before a municipal police would.

These various university-related forces could even result in a sort of "campus policing culture" (Author, XXXX), such as that described by Participant 12, where CP officers exercise more discretion and leniency toward students as compared to the more legalistic MP[ㅁ]:

It's a different culture [among the two police groups]. I feel like the campus police try to deter you ... like they're more prone to give you a second chance than city police ... [b]ecause I guess they've been around the campus more. They know students are in college [and] ... make mistakes; it's gonna happen.

\section{Danger}

In the field, policing involves preventing, discovering, and investigating crimes, as well as interacting with suspects, victims, and other community members. While performing these duties, officers are in danger of being deemed a threat by an offender or deserving of retaliation for some perceived wrongdoing.

Though danger is a facet of police work for CP and MP, the majority of participants perceived the former to face less risky situations than the latter. Students offered several explanations of this view. One is their belief that there are fewer guns on campus than the wider community. Participant 50 put it this way: "Most of us [students] don't carry guns on campus so their [campus officers'] life is not threatened as much [as municipal officers']." Participant 6 added, "[W]e know that a lot more crazy stuff happens out on the streets. It's not as many guns on campus as there are on the streets."

Another reason students perceive campus policing as less dangerous is the assumption that CP encounter far less crime than MP. "[T]he municipal police are more exposed to more crime than the campus police. The campus police are just responsible for the campus," said Participant 48. By the same token, Participant 40 remarked: "[T]ypically not much goes on on-campus comparable to the city streets." And Participant 7 explained:

[M] unicipal police have to deal with situations and go places that campus police do not, ... [like] some of the more crime-ridden neighborhoods, and this [campus] is not crime-ridden. ... The campus itself is not crime-ridden from a municipal standpoint. 
In more specific terms, some participants argued that when officers conduct more stops, they increase the opportunity for encountering danger. Participant 59, for example, reasoned that "[CP] are not doing traffic stops," which, while an overstatement, nonetheless meant to her, "They don't have to walk up on people who may shoot them if they go to they car." Participant 46 made a similar observation: "I feel municipal police officers run a little bit higher risk because you're pulling over traffic stops. ... You don't know who that ... person is behind that window in the car."

In addition to the issue of frequency is students' perception that, compared to CP, MP are at greater risk because they come across more serious crime. Participant 53 figured, "The types of crime on campus are a lot different than what the municipal police deals with. Municipal police deal with a lot more aggressive crime." Participant 1 gave the example of "[y]ou're less likely to get a call to go to a shooting if you're stationed on a campus, especially [this university], where that doesn't happen often." Participant 23 explained that "[MP] can be faced with anything, any minute of the day. ... [They] can be called to [a] burglary, child molestation, murder, a shooting, robberies, domestic violence. Those issues, campus police do not face on a daily basis." The following quotes further illustrate the point:

Participant 30: I mean the ... environments are so different. The environment of [this university] is a very laid back environment. ... I never really hear too much going on. The most we have is someone having an asthma attack. We don't have where someone just got shot and is in need of crime scene investigation, things like that.

Participant 3: [Y]ou do get different things on a campus than you would just out in the world. It won't just be like, 'Oh people robbed a bank.' That can't really happen on a campus [because there's no bank]. ... Most of the time it's pretty much the same thing: somebody's drinking alcohol; somebody's having a party, tell them to quiet down; somebody's smoking weed or something; but other than that, it's not like somebody's robbing something.

Part of what a makes a situation dangerous is who is involved, of course. Whereas CP tend to deal with "students," noted Participant 22, "municipal [police] have a variety. They could run into any kind of people." "[There are] different type[s] of people that are on campus ... from those that are in the streets," is how Participant 62 put it. Some 
participants perceived that MP more frequently encounter more dangerous people than do CP. Consider what Participant 26 said about the matter:

[Students] have something going for themselves and don't have the mentality that someone who doesn't have anything going for themselves [a nonstudent] might have. I feel like most of the people that campus police encounter are actually ... a better grade of person, normally.

Participant 19 was more explicit in how students and others compare: "I don't think there as many violent people on campus as there is out there in the world."

There were participants, however, who thought danger applied more or less equally to $\mathrm{CP}$ and MP. "[W]hether you're [an] on-campus or off-campus police officer," explained Participant 14, "the risk would still be the same as far as endangerment." The thinking behind this position was that, to quote Participant 2, "The same thing could happen here [on campus] just as it could off campus." Participant 20 stated, "Just because the campus police setting is campus, doesn't make it any different. Same crimes could happen on campus that happen off campus or in other cities or whatever." Participant 11 explained, "Regardless of what kind of policeman you are, you still dealing with people so you could still get attacked. You could still get hit, beat, or whatever." And in Participant 47's mind, "[CP] are subject to facing the same potential criminals as if [they] were on [a local road] or something."

The same argument - namely, anything could happen anywhere - also popped up when some students discussed the risk of CP and MP encountering armed suspects. For example, Participant 20 reasoned, "You never know what could happen on campus or who ... might have a gun in their car, a gun in their room, so yeah, it's just the same [danger as MP]." Participant 52 argued, "You never know who is out there, who was crazy and is not, who was carrying a gun and is not. It can always escalate into something more." And a similar stance was shared by Participant 55:

[A]nything can happen anywhere. A municipal police officer's life is in danger when you get out of the car to make a traffic stop, just like the campus police life is in danger when he is walking the campus and there is a would-be gunman out. You never know. Their lives are still in the same amount of jeopardy.

As armed suspects go, the worst case scenario envisioned by participants - and one used to explain why they think danger is similar for $\mathrm{CP}$ and $\mathrm{MP}$ - is the prospect of a mass shooting at school. When Participant 62 was asked to explain why she thinks CP 
and MP face a comparable amount of danger, she answered: "[Y]ou might have some time you have to deal with someone who may have a weapon. We have heard of campus shootings before so it could be just as dangerous." Asked the same question, Participant 5 responded:

Because someone can shoot like weapons of mass destruction, like bombs, or anything can be targeted on campus or outside of campus. I feel like their [CP] life is just [as] at [much] risk as regular police. They could get shot, killed. They could come into the same encounters with the same types of crime as municipal police."

A couple of participants initially stated that municipal policing is more dangerous than campus policing, until, that is, they reflected on the risk of a mass shooting on campus:

Participant 56: In a city you have more ... come to think of it, you have the Virginia shooting and all of that. ... Other than an active shooter, I don't think they [CP] are more at risk. Everybody is at risk then anyways if you have an active shooter on campus.

Participant 60: [I]t [campus policing] can be as dangerous. I think on the average day it is not as dangerous because you never know what you are going to come across working in the city. At the same time, you can have a school shooting here.

When it comes to comparing on-the-job danger faced by CP and MP, perhaps Participant 18 said it best: "I mean, statistically ... it's not that many school shootings as people would think there is, but when you put your life on the line every day, it's dangerous. You never know what might happen."

\section{Discussion and Conclusion}

Participants perceived CP and MP as different in five respects: training; resources; powers; sanctioning severity; and, danger. Compared to MP, students figured CP receive less training and different training more oriented toward campus issues. Participants spoke to CP lacking resources, like "man power," that make them less equipped to handle serious situations. Respondents said CP may have less power to arrest suspects, investigate crimes, and police outside their primary jurisdiction. Interviewees were of the impression that $\mathrm{CP}$ are less prone to severely sanction suspects, or sanction them at all, due to several factors, including a better 
understanding of college life, being more acquainted with students, and being more invested in students' success. Finally, students described the work of CP as less dangerous due to encountering less crime generally and less crime of a serious nature, as well as having fewer interactions with citizens who possess firearms or are otherwise treacherous.

However, a unique feature of this paper is it also shed light on how students see CP as similar to MP and, thus, "real" police. Relative to MP, some interviewees figured that $\mathrm{CP}$ partake in the same training and thereby gain the same certifications. Participants mentioned that CP have weapons, bulletproof vests, police cars, and share other resources. Students described CP work as equally dangerous because anything could happen anywhere. Respondents said CP have the powers to investigate offenses, sanction suspects, and, if necessary, use weapons against them. However, and despite recognizing those powers, participants uniformly were of the impression that CP are unique in how they sanction as they tend to be far more lenient; to put it differently, then, no participant saw CP and MP as the same in that regard.

What are the implications of these findings for future research and (campus) crime control? Regarding the former, the most obvious implications are a consequence of the present study's limitations. For one, its qualitative focus and nonrandom sampling method mean that the findings have an unknown generalizability. To be clear, this is not a crucial problem for the present paper because its purpose has been to uncover how students see CP and MP as alike and different, not to quantitatively document the extent to which any given view is held. With that said, a logical next step is to gather and analyze quantitative data on the extent to which each perspective is held, as well as to test theories of why such views vary and to what effects. Better yet, of course, would be to gather such data via sampling techniques that allow for a known degree of generalizability.

One limitation of the present paper suggests a pathway for future qualitative research. As mentioned in the section describing data collection, the findings herein are based on participants' answers to five questions about how CP and MP compare. These questions pertained to the groups' respective capability to fight crime and importance in doing so; the extent to which they should and do possess the same powers; and, danger faced at work. As with any study, certain questions may lead to certain answers, which is to say other questions may lead to other answers. It follows, then, that in future qualitative work, researchers could further inform the range of ways that 
students see CP relative to MP by asking the same or entirely different questions. Either way, the same or different answers may result.

Yet another limitation of the present paper, namely its focus on general perceptions rather than those tied to specific incidents, provides an opportunity for both quantitative and qualitative researchers. This paper's focus has been general perceptions of CP versus MP. An alternative approach is to focus on perceptions that emerge out of specific interactions with CP or MP. In addition to being stopped for an offense, students - and citizens more broadly - may encounter CP or MP when calling on them for help, witnessing a crime, or simply during the course of normal, everyday life. Thus, researchers could expand understanding of how people see CP relative to MP by looking not only at general perceptions but also those emerging from various kinds of interactions.

This paper's goal has been conceptual: to ethnographically understand the ways in which students see CP versus MP. This is an important first step in theory development because theories are built on conceptual knowledge (Homans, 1967). Now that more light is shed on the issue, scholars are better positioned to answer two basic theoretical questions at stake: Why do people come to hold particular perceptions of $\mathrm{CP}$ versus MP? And, what are the effects of these perceptions on behavior? There a number of existing theoretical perspectives that could be used to answer the above questions, including - but certainly not limited to - those of Sykes and Clark (1975), Tyler (2004), and Black (1976).

This article began with several headlines questioning, to quote one outlet, "Are campus police officers 'real' police officers?" (Chronicle, 2015a). As with many issues in social life, this question is not simply a matter of concrete reality but also subjective reality. In many concrete respects, CP are as "real" as MP (Reaves, 2015a). Yet, the subjective aspects of the questions are more complex. Some participants in the present study, for instance, viewed CP and MP as basically one in the same, minus the obvious jurisdictional difference. Other participants perceived CP and MP to be quite distinct, thinking the former even lacked the power to arrest suspects. The origin, nature, and consequences of perceptions are interesting in their own right (perhaps especially to persons who frequently come across CP at work), but, they also hold practical importance for suggesting how to improve policing and thereby better control crime both on campus and off.

Given that this paper is an early step toward a fuller understanding of how, why, and to what extent students perceive CP relative to MP, it is important not to go too far with 
practical suggestions. With that caveat in mind, however, it is apparent that CP departments should seek to further instill positive evaluations of CP in students' minds and reshape unwarranted perceptions. CP could disseminate the "facts" about what they are vested with and (can) do on the job by visiting university orientation sessions or classes, as well as by posting flyers on and around campus, among other ways. Three pieces of information seem most important and practical to shape. Namely, CP should bolster others' perceptions of them as 1) interested in student welfare; 2) able to prevent and handle crime due to their training and resources; and, 3) possessing traditional policing powers such as the ability to arrest. All of these "information items" may improve the perceived legitimacy of CP and, in turn, improve students' willingness to call on and cooperate with them. Additionally, the third item may prevent campus police-citizen encounters from becoming contentious and even violent.

\section{References}

Author (XXXX).

Allen A and Jacques S (2013) Alcohol-Related Crime among College Students: A Review of Research and Fruitful Areas for Future Work. Criminal Justice Studies 26: 478-494.

Anderson MD (2015. September 28) The Rise Of Law Enforcement On College Campuses. The Atlantic. Available at: http://www.theatlantic.com/education/archive/2015/09/college-campuspolicing/407659/.

Bittner E (1990) Aspects of Police Work. Boston, MA: Northeastern University Press. Black D (1976) The Behavior of Law. New York, NY: Academic Press.

Bordner DC and Petersen DM (1983) Campus Policing: The Nature of University Police Work. Maryland: University Press of America.

Bromley ML and Reaves BA (1998) Comparing Campus and City Police Operational Practices. Journal of Security Administration 21: 41-54.

Bromley ML and Reaves BA (1999) Comparing the Practices and Policies of Sworn and Non-Sworn Campus Police Departments within the Context of the Campus Security Act of 1990. Criminal Justice Policy Review 9: 261-278. 
Brown MK (1981) Working the Street: Police Discretion and the Dilemmas of Reform. New York, NY: Russell Sage.

Carr JL and Ward RL (2006) ACHA Campus Violence White Paper. NASPA 43: 380409.Chappell AT et al. (2010) Law Enforcement Training: Changes and Challenges. In: Dunham RG and Alpert GP (eds) Critical Issues In Policing: Contemporary Readings ( $6^{\text {th }}$ ed). Long Grove, IL: Waveland Press, pp. 53-70.

Dowdall GW (2013) The Role of Alcohol Abuse in College Student Victimization. In Fisher BS and Sloan JJ (eds) Campus Crime: Legal, Social, and Policy Perspectives (3 ${ }^{\text {rd }}$ ed). Springfield, IL: Charles C. Thomas Publisher, pp. 184-210.

Fisher BS and Sloan JJ (eds.) (2007). Campus Crime: Legal, Social, and Policy Perspectives ( $2^{\text {nd }}$ ed.). Springfield, IL: Charles C. Thomas Publisher.

Glaser B and Strauss A (1967) The Discovery of Grounded Theory: Strategies For Qualitative Research. New York, NY: Aldine Transactions.

Georgia Bureau of Investigation (GBI) (2014) 2014 Summary Report, Uniform Crime Reporting (UCR) Program, Georgia Crime Information Center. Available at:

https://gbi.georgia.gov/sites/gbi.georgia.gov/files/related_files/site_page/2014CrimeStat isticsSummaryReport.pdf.

Gehrand KA (2008) Higher Education Policing: The New Millennium. International Association of Campus Law Enforcement. Available at: http://www.iaclea.org/visitors/PDFs/IACLEA-ContentPages_67-126.pdf.

Homans GC (1967) The Nature of Social Science. New York, NY: Harcourt, Brace and World.

Jacobsen SK (2015) Policing the Ivory Tower: Students' Perceptions of the Legitimacy of Campus Police Officers. Deviant Behavior 36: 310-329.

Jacques S (2014) The Quantitative-Qualitative Divide in Criminology: A Theory of Ideas' Importance, Attractiveness, and Publication. Theoretical Criminology 18: 317334.

Klinger D (1997) Negotiating Order in Patrol Work: An Ecological Theory of Police Response to Deviance. Criminology 25: 277-306. 
Manning PK (1977) Police Work: The Social Organization Of Policing. Cambridge, MA: Waveland Press.

Mayer E (2014) Campus Police: Real Deal or Rent-A-Cops? Available at: https://www.wbez.org/shows/curious-city/campus-police-real-deal-orrentacops/d66bc55e-4fb7-4dd7-bfca-4bc7a9350380.

Miller JL and Pan MJ (1987) Student Perceptions of Campus Police: The Effects of Personal Characteristics and Police Contacts. American Journal of Police 6: 27-44.

Muir WK Jr (1977) Police: Street Corner Politicians. Chicago, IL: University of Chicago Press.

Paoline EA and Sloan JJ (2003) Variability in the Organizational Structure of Contemporary Campus Law Enforcement Agencies: A National-Level Analysis. Policing 26: 612-639.

Patten R et al. (2016) The Continued Marginalization of Campus Police. Policing 39: 566-583.

Peak KJ et al. (2008) Campus Policing in America: A Twenty-Year Perspective. Police Quarterly 11: 239-260.

Powell J (1994) The Beginning - Yale Campus Police Department - 1894. Campus Law Enforcement Journal 24: 2-5.

Reaves BA (2008) Campus Law Enforcement, 2004-05, Special Report. Report for the U.S. Department of Justice, Office of Justice Programs. Report no. NCJ 219374, February. Washington, DC: Bureau of Justice Statistics.

Reaves BA (2015a) Campus Law Enforcement, 2011-12, Special Report. Report for the U.S. Department of Justice, Office of Justice Programs. Report no. NCJ 248028, January. Washington, DC: Bureau of Justice Statistics.

Reaves BA (2015b) Local Police Departments, 2013: Equipment and Technology Report for the U.S. Department of Justice, Office of Justice Programs. Report no. NCJ 248767, July. Washington, DC: Bureau of Justice Statistics.

Reaves B and Goldberg M (1996) Campus Law Enforcement Agencies, 1995. Report for the U.S. Department of Justice, Office of Justice Programs. Reports no. NCJ 161137, December. Washington, DC: Bureau of Justice Statistics. 
Shorey RC et al. (2011) Dating Violence and Substance Use in College Students: A Review of the Literature. Aggression and Violent Behavior 16: 541-550.

Sloan JJ (1992) The Modern Campus Police: An Analysis of their Evolution, Structure, and Function. American Journal of Police 11: 85-104.

Sloan JJ III and Fisher BS (2011) The Dark Side Of The Ivory Tower: Campus Crime As A Social Problem. Cambridge, UK: Cambridge University Press.

Sunshine J and Tyler TR (2003) The Role of Procedural Justice and Legitimacy in Shaping Public Support for Policing. Law \& Society 37: 512-548.

Sykes R and Clark J (1975) A Theory of Deference Exchange in Police Citizen Encounters. American Journal of Sociology 81: 584-600.

The Chronicle of Higher Education [chronicle] (2015a, July 27) Are campus police officers "real" police officers? An answer to that and other questions:

http://chroni.cl/1VJ $\underline{H 3 O N}$ [Tweet]. Available at: https://twitter.com/search? q=Are\%20campus\%20police\%20officers\%20\%E2\%80\%98real\%E2\%80\%99\%20police\% 20officersandsrc $=$ typd.

The Chronicle of Higher Education [chronicle]. (2015b, August 1) What are campus police allowed to do?: http://chroni.cl/1M3qPwZ [Tweet]. Available at: https://twitter.com/search? $\mathrm{q}=$ What\%20are\%20campus\%20police\%20allowed\%20to\%20do\%3Fandsrc=typd.

Tyler TF (2002) A National Survey for Monitoring Police Legitimacy. Justice Research and Policy 4: 71-86.

Tyler TR (2004) Enhancing Police Legitimacy. The Annals of the American Academy of Political and Social Science 593: 84-99.

Tyler TR (2006) Why People Obey the Law. New Jersey: Princeton University Press.

U.S. Census Bureau (USCB) (2015) United States Census Quickfacts. Washington, DC: United States Department of Commerce.

U.S. Department of Education (USDOE), Office of Postsecondary Education (2015) Distribution of Federal Pell Grant Program Funds by Institution, 2013-14. Washington, DC: United States Department of Education. 
U.S. Department of Education (USDOE) Office of Postsecondary Education (2016) Campus Safety and Security Data Analysis Cutting Tool. Washington, DC: United States Department of Education.

U. S. Department of Justice, Federal Bureau of Investigation (FBI) (2014) Crime in the United States 2014: Uniform Crime Reports. Washington, DC: Government Printing Office.

Vander Ven T (2011) Getting Wasted: Why College Students Drink Too Much And Party So Hard. New York, NY: New York University Press.

Wada JC et al. (2010) Betwixt and Between: The Perceived Legitimacy of Campus Police. Policing 33: 114-131.

Weiss KG (2013) Party School: Crime, Campus, and Community. Boston, MA: Northeastern University Press.

Westley WA (1970) Violence and the Police: A Sociological Study of Law, Custom and Morality. Cambridge, MA: MIT Press.

White House Task Force. (2014), Not Alone: The First Report Of The White House Task Force To Protect Students From Sexual Assault. Available at: http://www.whitehouse.gov/sites/default/files/docs/report_0.pdf.

Wilson J (1968) Varieties of Police Behavior: The Management of Law and Order in Eight Communities. Cambridge, MA: Harvard University Press.

Wolf R et al. (2007) Fighting Campus Crime: Perceptions Of Police Canines At A Metropolitan University. Critical Issues in Justice \& Politics 3: 1-18.

\section{Notes}

[1] POST stands for Peace Officer Standards and Training.

[2] To say a study "explicitly considers" perceptions of CP versus MP means that the analyzed data include quantitative or qualitative information on both types of police, or at least proxy measures of both groups. Thus, this section does not review studies of only CP, though they could be used to make inferences about how they compare to MP (see, e.g., Patten et al., 2016).

[]ㅡ The number of patrol officers in the department may vary month to month depending on turnover and promotions. 
[4] Students' perceptions may be informed by lived and/or vicarious experiences. For this study, the questions asked of participants do not distinguish between the two as the more central focus was on perceptions generally. Of course, future research should consider whether and how students' lived versus vicarious experiences affect their views of CP relative to MP. Perhaps, certain types of experiences affect certain types of views.

[]ㅡ To the author's knowledge, no study has empirically explored whether CP are actually more lenient toward students than MP. And to be clear, the notion that CP handle students more leniently than MP is perceptual. 